\title{
Tracer migration experiments in unsaturated fractured tuff
}

\author{
Qinhong Hu,* Robert C. TRautZ and Joseph S. Y. WANG \\ Earth Sciences Division, Lawrence Berkeley National Laboratory, 1 Cyclotron Road, MS 90-1116, Berkeley, CA 94720, U.S.A.
}

(Received April 15, 2003; Accepted October 7, 2003)

\begin{abstract}
Field tracer experiments were conducted at an underground tunnel—the Exploratory Studies Facility (ESF)—at Yucca Mountain, Nevada, to investigate the localized preferential flow and transport resulting from multiple episodic liquidrelease tests in unsaturated fractured tuff. Liquid was released into an isolated test interval ( $0.30 \mathrm{~m}$ long) within a borehole drilled along ESF. Out of 60 liquid-release tests, 36 contained tracers (mostly food and fluorescent dyes) to help us to elucidate the flow paths in unsaturated tuff. After the tracer-migration test, an array of 12 boreholes was drilled into the test area to collect rock samples. These samples were then analyzed to delineate the extent of tracer migration. Complementary laboratory column transport studies using crushed rock showed that the dye tracers were-at most—very weakly sorbed to the tuff matrix. We found that the tracer-migration test, with a limited release volume of $1.5 \mathrm{~L}$, resulted in a localized distribution of tracers, most likely confined to a $1.0 \times 1.6-\mathrm{m}$ area directly below the test interval (over a vertical experimental length of about $0.65 \mathrm{~m}$ ). This conclusion was corroborated by detecting dyes that had been introduced during previous liquid-release seepage tests either before or after niche excavation; the spatial distribution of all dyes was near their individual release intervals. Limited lateral spreading of the dyes occurred, even when several non-dyecontaining seepage tests were intermittently conducted following dye release. This work also demonstrates the utility of applying multiple tracers (including food and fluorescent dyes) to help delineate transport characteristics in unsaturated fractured rock.
\end{abstract}

Keywords: tracer, unsaturated, fracture, flow path, rock

\section{INTRODUCTION}

Fracture flow plays an important role in water flow and contaminant transport in unsaturated and saturated fractured rock. In unsaturated fractured rock with low permeability, water flows predominantly through the interconnected fracture network, with some water imbibing into the neighboring matrix rock. The mass transfer of contaminants between the fractures and the rock matrix is driven by imbibition (from the capillary pressure gradient) or by diffusion (from the concentration gradient). Both imbibition and diffusion into the rock matrix can move contaminants away from the flowing fracture, thereby contributing to the retardation of the contaminants. However, accumulating data show that water is able to flow along "fast paths" provided by partially saturated fractures (e.g., Nicholl et al., 1994; Tokunaga and Wan, 1997; Pruess, 1998; Su et al., 1999; Faybishenko et al., 2000; Hu et al., 2002; Glass et al., 2002). These preferential fast paths reduce both the flow through the matrix

\footnotetext{
*Corresponding author (e-mail: hu7@1lnl.gov)

Present address: Lawrence Livermore National Laboratory, 7000 East Avenue, L-231, Livermore, CA 94550, U.S.A.

Copyright $($ C 2004 by The Geochemical Society of Japan.
}

and the interface area for fracture-matrix interaction, thus limiting the effect of potential retarding processes such as matrix diffusion and sorption.

Pruess (1999) proposed a conceptual model that hypothesizes how water can flow relatively freely through networks of interconnected fractures in the presence of strong suction pressures from an unsaturated rock matrix. His model conceptualizes fracture flow as a spatially localized and transient (intermittent) process. However, Pruess noted that direct field observations remain incomplete and ambiguous. The study described in this paper was conducted to provide field observations regarding flow and transport in unsaturated fractured rock.

It is very important to understand the significance of localized preferential flow through unsaturated fractured rock, considering the potential consequence of accelerated water travel and contaminant transport. This has direct relevance to the understanding of transport processes for fractured tuff at Yucca Mountain, Nevada, which is currently under consideration as a potential underground, high-level radioactive-waste repository. The objective of this study was to investigate the occurrence of localized flow paths in unsaturated fractured tuff. This paper describes a series of liquid-release tests that were conducted in the Exploratory Studies Facility (ESF) of Yucca Mountain and that used multiple tracers. These tracers helped 
us to elucidate flow paths and to evaluate the significance of preferential flow within the unsaturated tuff. Rock core samples were collected from borehole drillings and were subsequently analyzed to delineate the extent of lateral tracer migration. The low detection limits of fluorescent dyes (achievable with a fluorescence spectrophotometer) provide confidence for the delineation of dye-stained flow paths. This work also showed the utility-for unsaturated flow and transport studies in fractured rock-of multiple tracers, including food and fluorescent dyes that have been used for water tracing in porous media (e.g., Smart and Laidlaw, 1977; McLaughlin, 1982; Flury and Fluhler, 1995; Kasnavia et al., 1999).

\section{Test Designs, Materials, and Methods}

\section{Field tracer studies}

Figure 1a shows the location map of a niche (Niche 3650) with respect to ESF and Yucca Mountain. The niche is a mined opening, approximately $4 \mathrm{~m}$ wide, $3 \mathrm{~m}$ high, and $9 \mathrm{~m}$ deep, on the wall of the ESF main drift. Figure $1 \mathrm{~b}$ presents an end view of the approximate location of the seven boreholes installed at the niche before it was excavated. The niche is within the Topopah Spring volcanic tuff, the potential repository geologic unit. The boreholes $(0.076 \mathrm{~m}$ in diameter and about $10 \mathrm{~m}$ in length) were dry core-drilled. Three upper boreholes, designated UL, UM, and UR (upper left, upper middle, and upper right), were drilled approximately $1 \mathrm{~m}$ apart and $0.65 \mathrm{~m}$ above the niche ceiling. The remaining boreholes (ML, $\mathrm{MR}, \mathrm{BL}$, and $\mathrm{BR}$ for middle left, middle right, bottom left, and bottom right, respectively) were drilled within the limits of the niche and were intentionally mined out when the niche was constructed, as described later in this paper.

Before the niche was excavated, two food dyes, FD\&C Blue No. 1 and FD\&C Red No. 40, were released into selected test intervals within the three upper boreholes (Table 1). The symbols "__" and " $\rightarrow$ " to the left side of the test-interval locations (the slanted black squares) in Fig. 2a represent the pre-excavation liquid-release tests of blue or red dyes. These pre-excavation tests were conducted to evaluate how far a finite pulse of liquid would travel through unsaturated fractured rock. Water containing colored dyes was used to mark the wetted area and flow path resulting from each release. The niche was then
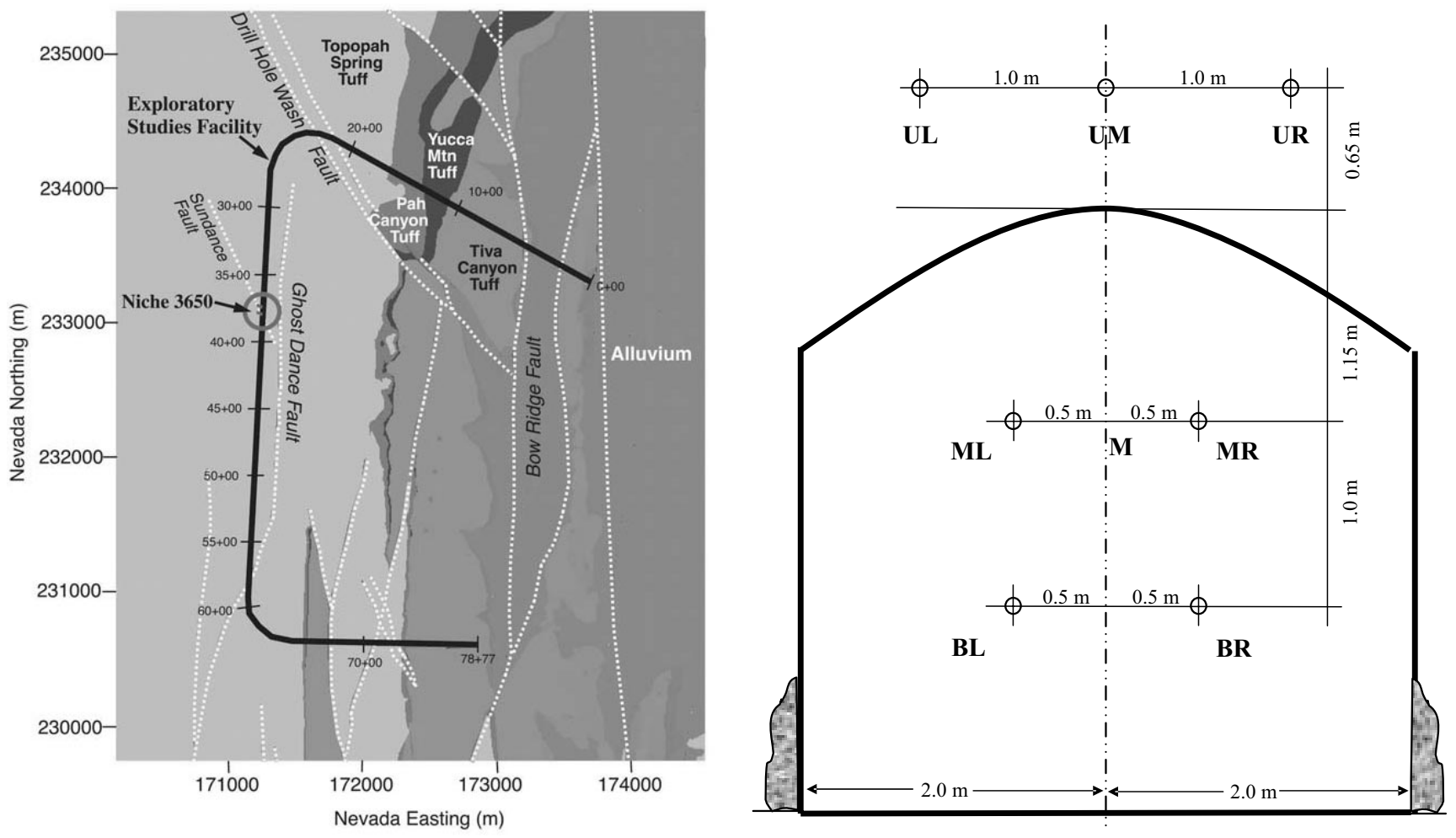

Fig. 1. (a) A location map of Niche 3650 with respect to the Exploratory Studies Facility (ESF) and Yucca Mountain. (b) An end view (modified from Wang et al., 1999) of the boreholes on the wall of the ESF main drift before Niche 3650 was excavated. Borehole designations: $B=$ bottom, $M=$ middle, $U=$ upper, $L=$ left, $R=$ right. All measurements are approximate and do not represent as-built conditions. 
excavated dry (using the mining machine Alpine Miner) so we could observe and photograph the distribution of fractures and dyes within the tuff. After the niche excavation, liquid-release tests were conducted to investigate seepage behavior into the niche (Table 2). These postexcavation seepage tests were used to quantify the occurrence and volume of water seeping into the niche from a localized water source of known duration and intensity and to evaluate seepage threshold (Wang et al., 1999). The dyes that were used included FD\&C Blue No. 1, Sulpho Rhodamine B, Pyranine, FD\&C Yellow No. 6, Acid Yellow 7, and Amino G Acid. The seepage test sequences before and after the niche excavation are schematically described in Fig. 2a.

All liquid-release tests (either with or without tracera total of 60 tests) were carried out by pumping liquid at a constant rate into $0.3-\mathrm{m}$-long test intervals isolated by a straddle packer system. The flow rate was controlled to maintain a fluid pressure at less than $5 \mathrm{~cm}$ of water in the test interval (Wang et al., 1999). The rate at which water was released into the formation ranged from 0.012 to 3.6 $\mathrm{mL} / \mathrm{s}$ for all tests, and the volume released ranged from 46.8 to $5,597.5 \mathrm{~mL}$ per test (with about $1,000 \mathrm{~mL}$ of liquid released for the majority of the tests, as permitted by the Yucca Mountain Project).

During the last test, here called a tracer-migration test, a liquid pulse was released into a previously identified, highly permeable zone located in borehole UM at an interval of 4.88-5.18 $\mathrm{m}$ from the borehole collar (Wang et al., 1999, Fig. 3). The liquid contained tracers of iodide, bromide, FD\&C Blue No. 1, and FD\&C Yellow No. 5.
Bromide and iodide were used as conservative tracers, while the dyes were applied to stain the rock. Twelve sampling boreholes, approximately $1.5 \mathrm{~m}$ long each, were then drilled dry into the niche ceiling. Figure $2 b$ shows a threedimensional view of the borehole array. The sampling boreholes measured $4.47 \mathrm{~cm}$ in diameter, and the rock samples that were collected from the boreholes were then divided into sections during coring, with each section wrapped separately in plastic. Each wrapped sample was placed inside a Lexan tube, sealed with tape on both ends, and placed in a sealed aluminum package. These rockcore samples underwent subsequent laboratory chemical analyses to determine the extent of tracer migration. In addition, several rock-chip samples were collected from the niche ceiling. These samples were taken from an area with a radius of about $20 \mathrm{~cm}$ that was directly below the release interval of the tracer-migration test.

$\mathrm{CaI}_{2}$ (purity 99\%), $\mathrm{NaI}$ (purity >99\%), $\mathrm{CaBr}_{2}$ (purity $>98 \%$ ) and Amino G Acid were obtained from Pfaltz and Bauer, Inc. FD\&C Blue No. 1 (purity 90\%), FD\&C Yellow No. 5 (purity 91\%), FD\&C Yellow No. 6 (purity 90\%), and FD\&C Red No. 40 (purity 90\%) were obtained from the Werner-Jenkinson Company (St. Louis, MO). Sulpho Rhodamine B was from the Keystone Aniline Corp. (Santa Fe Spring, CA). Pyranine and Acid Yellow 7 were purchased from TCI America (Portland, OR). The dyes with no manufacturer-provided purity information were used as received, since the dyes were intended to help delineate flow paths-a purpose served by relative dye concentrations.

Table 1. Pre-excavation liquid-release summary

\begin{tabular}{|c|c|c|c|c|c|c|c|}
\hline Borehole location & Test date & $\begin{array}{l}\text { Depth of release } \\
(\mathrm{m})\end{array}$ & Tracer & $\begin{array}{c}\text { Tracer conc. } \\
(\mathrm{g} / \mathrm{L})\end{array}$ & $\begin{array}{l}\text { Average release rate } \\
(\mathrm{mL} / \mathrm{s})\end{array}$ & $\begin{array}{l}\text { Release time } \\
\text { (min) }\end{array}$ & $\begin{array}{c}\text { Mass released } \\
(\mathrm{mL})\end{array}$ \\
\hline \multirow[t]{5}{*}{ Middle } & $6 / 4 / 97$ & $2.13-2.44$ & RN40 & 7.9 & 3.6 & 4.42 & 941.7 \\
\hline & $6 / 4 / 97$ & $2.77-3.05$ & AY7 & 1.9 & 3.4 & 4.25 & 120.3 \\
\hline & $6 / 3 / 97$ & $3.35-3.66$ & YN6 & 8.3 & 3.5 & 4.50 & 140.5 \\
\hline & $6 / 3 / 97$ & $3.96-4.27$ & SRB & 2.0 & 3.3 & 4.17 & 144.2 \\
\hline & $6 / 3 / 97$ & $4.57-4.88$ & BN1 & 8.4 & 3.4 & 4.42 & 474.0 \\
\hline \multirow[t]{4}{*}{ Upper left } & $8 / 7 / 97$ & $5.18-5.49$ & BN1 & 8.4 & 2.0 & 8.31 & 103.2 \\
\hline & $8 / 7 / 97$ & $5.79-6.10$ & RN40 & 8.7 & 2.0 & 8.43 & 276.6 \\
\hline & $8 / 7 / 97$ & $6.40-6.71$ & $\mathrm{BN} 1$ & 8.4 & 2.9 & 5.67 & 46.8 \\
\hline & $8 / 7 / 97$ & $7.01-7.32$ & RN40 & 8.7 & 2.0 & 8.47 & 694.5 \\
\hline \multirow[t]{5}{*}{ Upper middle } & $8 / 7 / 97$ & $4.27-4.57$ & $\mathrm{BN} 1$ & 8.8 & 0.022 & 771.4 & 675.8 \\
\hline & $8 / 6 / 97$ & $4.88-5.18$ & RN40 & 7.7 & 3.0 & 5.48 & 937.4 \\
\hline & $8 / 7 / 97$ & $5.49-5.79$ & $\mathrm{BN} 1$ & 8.4 & 2.1 & 8.06 & 115.7 \\
\hline & $8 / 7 / 97$ & $6.10-6.40$ & RN40 & 8.7 & 0.5 & 36.6 & 106.8 \\
\hline & $8 / 6 / 97$ & $6.71-7.01$ & BN1 & 7.7 & 1.9 & 8.20 & 438.7 \\
\hline \multirow[t]{2}{*}{ Upper right } & $8 / 7 / 97$ & $1.52-1.83$ & RN40 & 7.8 & 2.0 & 7.63 & 369.9 \\
\hline & $8 / 7 / 97$ & $2.13-2.44$ & BN1 & 8.4 & 2.0 & 8.50 & 999.8 \\
\hline \multirow[t]{2}{*}{ Middle left } & $8 / 8 / 97$ & $4.88-5.18$ & SRB & 2.0 & 1.9 & 6.73 & 151.6 \\
\hline & $8 / 8 / 97$ & $6.71-7.01$ & SRB & 2.0 & 2.0 & 8.22 & 170.9 \\
\hline Middle right & $8 / 8 / 97$ & $5.18-5.49$ & SRB & 2.0 & 1.9 & 8.07 & 308.3 \\
\hline
\end{tabular}

RN40: FD\&C Red No. 40; AY7: Acid Yellow 7; YN6: FD\&C Yellow No. 6; SRB: Sulpho Rhodamine B; BN1: FD\&C Blue No. 1. 


\section{Legend}

: The release interval for tracer-migration test.

(1) - (12): Twelve sampling boreholes.

\section{Niche 3650}

$\bullet$ : Test interval location

$\begin{array}{ll}-10 & \text { Shows sequence of dye/water used in each test interval; } \\ \therefore 3 & \text { hypothetical number " } 0 \text { " denotes the time of niche exca }\end{array}$

Pyranine

Sulfo Rhodamine B

Amino G Acid

Acid Yellow 7

FD\&C Blue No. 1

FD\&C Blue No. 1

\& FD\&C Yellow No. 6

FD\&C Red No. 40

No dye
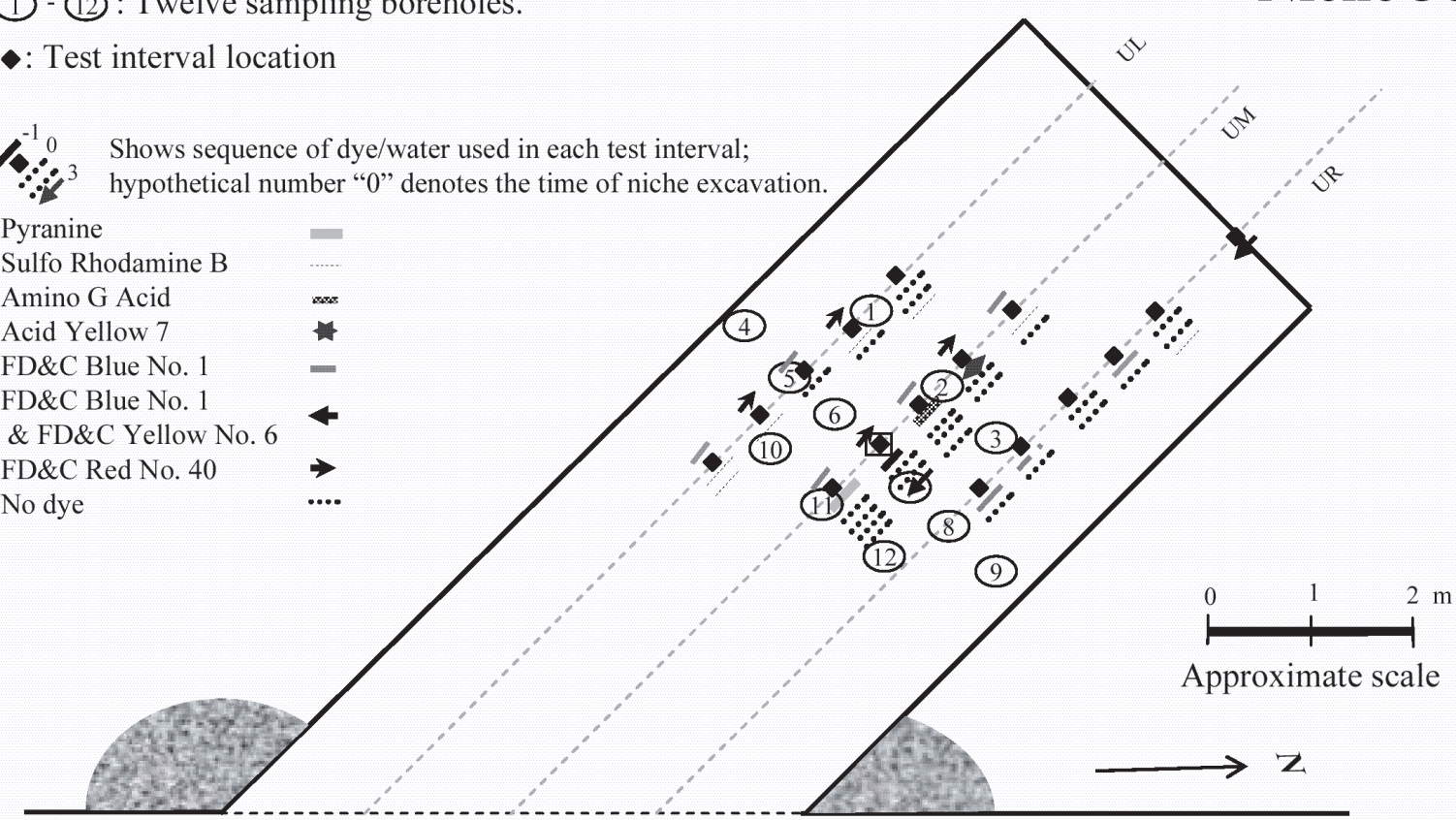

Approximate scale

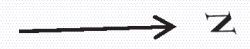

ESF main drift

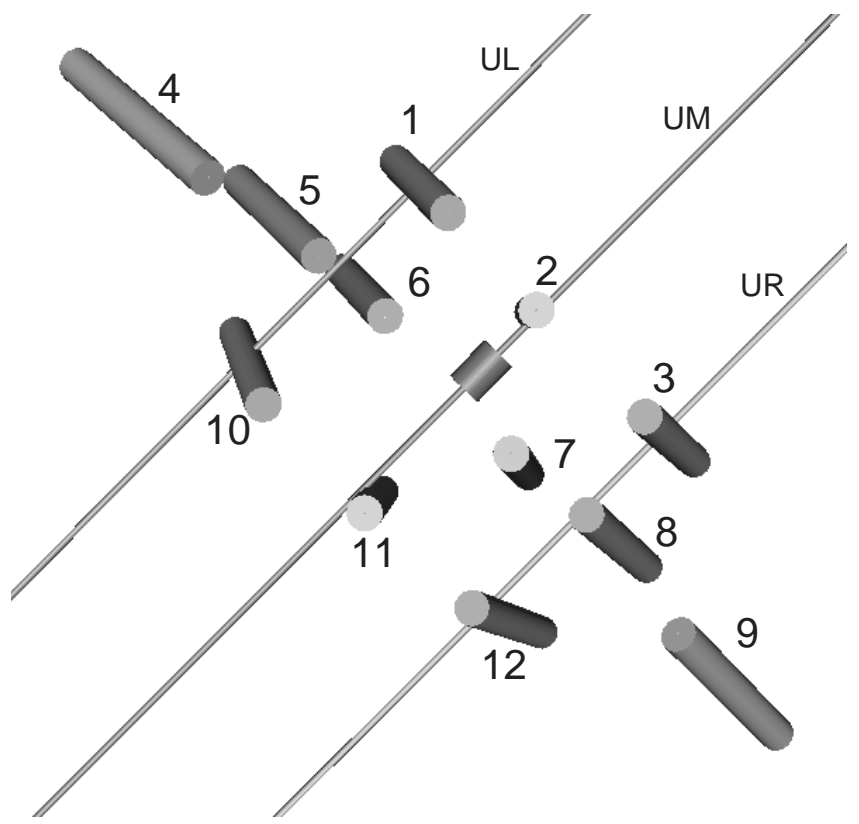

Fig. 2. (a) Schematic plan view of sampling borehole array and liquid-releaseldye application history. All measurements are approximate and do not represent surveyed as-built conditions. (b) The three-dimensional prospective view, based on as-built coordinates (the distance between $U L$ and $U M$ is $1 \mathrm{~m}$ ), of the sampling borehole array, as viewed inside the niche looking up toward the niche ceiling; the numbers 1 to 12 identify each borehole. 
Table 2. Post-excavation liquid-release summary

\begin{tabular}{|c|c|c|c|c|c|c|c|c|}
\hline Borehole location & Test date & $\begin{array}{c}\text { Depth of release } \\
\text { (m) }\end{array}$ & Tracer & $\begin{array}{c}\text { Tracer conc. } \\
(\mathrm{g} / \mathrm{L})\end{array}$ & $\begin{array}{c}\text { Average } \\
\text { release rate } \\
(\mathrm{mL} / \mathrm{s})\end{array}$ & $\begin{array}{c}\text { Release time } \\
(\min )\end{array}$ & $\begin{array}{c}\text { Mass released } \\
(\mathrm{mL})\end{array}$ & $\begin{array}{l}\text { Seepage mass } \\
\text { captured } \\
(\mathrm{mL})\end{array}$ \\
\hline \multirow[t]{9}{*}{ Upper left } & $12 / 11 / 97$ & $5.18-5.49$ & SRB & 1.4 & 0.190 & 87.63 & 405.4 & 0 \\
\hline & $2 / 12 / 98$ & $5.18-5.49$ & SRB & 1.4 & 0.014 & 1227.0 & 537.3 & 0 \\
\hline & $12 / 11 / 97$ & $5.79-6.10$ & SRB & 1.1 & 0.528 & 31.72 & 379.2 & 0 \\
\hline & $12 / 11 / 97$ & $6.40-6.71$ & None & 0 & 0.502 & 33.22 & 420.3 & 0 \\
\hline & $12 / 10 / 97$ & $7.01-7.32$ & SRB & 2.0 & 1.949 & 8.58 & 1005.5 & 16.0 \\
\hline & $1 / 6 / 98$ & $7.01-7.32$ & None & 0 & 0.190 & 88.07 & 1001.0 & 0 \\
\hline & $1 / 6 / 98$ & $7.62-7.92$ & None & 0 & 0.507 & 33.75 & 1025.4 & 279.7 \\
\hline & $2 / 12 / 98$ & $7.62-7.92$ & None & 0 & 0.101 & 171.1 & 1035.1 & 156.9 \\
\hline & $3 / 4 / 98$ & $7.62-7.92$ & SRB & 2.0 & 0.012 & 1386.0 & 1037.3 & 59.8 \\
\hline \multirow[t]{20}{*}{ Upper middle } & $11 / 13 / 97$ & $4.27-4.57$ & Pyranine & 3.1 & 2.019 & 8.45 & 1008.7 & 228.0 \\
\hline & $12 / 3 / 97$ & $4.27-4.57$ & None & 0 & 0.503 & 33.87 & 1015.7 & 235.4 \\
\hline & $12 / 3 / 97$ & $4.27-4.57$ & None & 0 & 0.506 & 33.78 & 1012.5 & 568.4 \\
\hline & $1 / 7 / 98$ & $4.27-4.57$ & None & 0 & 0.047 & 359.1 & 1004.2 & 46.0 \\
\hline & $2 / 10 / 98$ & $4.27-4.57$ & None & 0 & 0.016 & 1176.0 & 1163.3 & 0 \\
\hline & $11 / 12 / 97$ & $4.88-5.18$ & SRB & 2.0 & 2.892 & 6.07 & 1033.1 & 99.6 \\
\hline & $12 / 4 / 97$ & $4.88-5.18$ & None & 0 & 0.507 & 34.58 & 1044.6 & 44.3 \\
\hline & $12 / 5 / 97$ & $4.88-5.18$ & None & 0 & 0.144 & 122.6 & 1049.3 & 74.7 \\
\hline & $1 / 8 / 98$ & $4.88-5.18$ & None & 0 & 0.047 & 375.5 & 1044.2 & 0 \\
\hline & $3 / 6 / 98$ & $4.88-5.18$ & YN6 \& BN1 & 3.4 & 0.013 & 7054.0 & 5579.5 & 0 \\
\hline & $3 / 6 / 98$ & $4.88-5.18$ & mixture* & see the note* & 0.013 & 1948.7 & 1520.0 & 0 \\
\hline & $11 / 13 / 97$ & $5.49-5.79$ & AGA & 3.1 & 2.069 & 8.22 & 1013.4 & 275.7 \\
\hline & $12 / 4 / 97$ & $5.49-5.79$ & None & 0 & 0.504 & 34.48 & 1033.7 & 222.1 \\
\hline & $1 / 9 / 98$ & $5.49-5.79$ & None & 0 & 0.058 & 299.7 & 1038.7 & 33.3 \\
\hline & $2 / 11 / 98$ & $5.49-5.79$ & None & 0 & 0.014 & 1276.3 & 1041.7 & 0 \\
\hline & $11 / 13 / 97$ & $6.10-6.40$ & AY7 & 1.6 & 0.514 & 32.42 & 100.3 & 0 \\
\hline & $12 / 4 / 97$ & $6.10-6.40$ & None & 0 & 0.192 & 86.92 & 989.4 & 0 \\
\hline & $1 / 12 / 98$ & $6.10-6.40$ & None & 0 & 0.792 & 21.15 & 1012.1 & 0 \\
\hline & $11 / 12 / 97$ & $6.71-7.01$ & SRB & 2 & 1.924 & 8.32 & 274.5 & 0 \\
\hline & $12 / 5 / 97$ & $6.71-7.01$ & None & 0 & 0.202 & 82.58 & 988.3 & 0 \\
\hline \multirow[t]{12}{*}{ Upper right } & $1 / 14 / 98$ & $4.27-4.57$ & $\mathrm{BN} 1$ & 4.1 & 0.198 & 84.88 & 995.7 & 4 \\
\hline & $2 / 5 / 98$ & $4.27-4.57$ & None & 0 & 0.055 & 304.77 & 1003.0 & 0 \\
\hline & $1 / 15 / 98$ & $4.88-5.18$ & BN1 & 1.6 & 0.190 & 89.67 & 1016.4 & 4.1 \\
\hline & $2 / 6 / 98$ & $4.88-5.18$ & None & 0 & 0.053 & 320.7 & 1013.5 & 0 \\
\hline & $1 / 13 / 98$ & $5.49-5.79$ & None & 0 & 0.251 & 67.75 & 904.3 & 0 \\
\hline & $2 / 10 / 98$ & $5.49-5.79$ & None & 0 & 0.981 & 17.33 & 377.8 & 49.7 \\
\hline & $1 / 14 / 98$ & $6.10-6.40$ & BN1 & 3.8 & 0.192 & 88.32 & 1013.6 & 270.7 \\
\hline & $2 / 4 / 98$ & $6.10-6.40$ & None & 0 & 0.057 & 297.0 & 1018.7 & 220.2 \\
\hline & $1 / 13 / 98$ & $6.71-7.01$ & None & 0 & 0.196 & 86.47 & 1010.2 & 312.4 \\
\hline & $2 / 3 / 98$ & $6.71-7.01$ & None & 0 & 0.102 & 167.93 & 1026.9 & 294.9 \\
\hline & $3 / 5 / 98$ & $6.71-7.01$ & SRB & 0.5 & 0.013 & 1280.62 & 1020.0 & 38.9 \\
\hline & $3 / 12 / 98$ & $7.62-7.92$ & YN6 \& BN1 & 3.4 & 0.013 & 1276.75 & 669.3 & 0 \\
\hline
\end{tabular}

AGA: Amino G Acid. Other abbreviations are same as Table 1.

*Tracer-migration test: the released tracer concentrations were $4.60 \mathrm{~g} / \mathrm{L} \mathrm{NaI}, 4.60 \mathrm{~g} / \mathrm{L} \mathrm{CaI}_{2}, 4.60 \mathrm{~g} / \mathrm{L} \mathrm{CaBr}, 1.56 \mathrm{~g} / \mathrm{L} \mathrm{FD \& C} \mathrm{Blue} \mathrm{No} .1$, and $1.76 \mathrm{~g} / \mathrm{L}$ FD\&C Yellow No. 5.

\section{Laboratory studies}

Core sample processing The rock contained in each sample package was further divided into sample intervals, approximately $10 \mathrm{~cm}$ in length, for tracer analysis. Rock samples within each interval were representatively subsampled for subsequent crushing, with visibly dyestained rocks - if any-proportionally sampled together with the nondyed rocks. Depending upon the rock recovery in each interval, the rock subsample used ranged from
40 to $90 \%$ of the total sample available for the interval. A jaw crusher and a Micro-Mill Grinder were then used to reduce the size of each rock subsample until it could pass through a $2-\mathrm{mm}$ sieve.

The depth interval for each rock subsample depended mainly on the depth-interval information provided on the sample packages; this information was recorded during coring. It was difficult to determine the exact location of each subsample when the samples consisted of highly 
fractured pieces or rubble, as was occasionally observed for some samples. In such cases, the actual recovered coredepth interval was less than the depth interval assumed. However, the majority of the core sample was intact, making the actual sample length quite comparable to the indicated sample interval.

For each sieved sample, $10 \mathrm{~g}$ was weighed, in duplicate, and then mixed with $20 \mathrm{~mL}$ of NANOpure water to facilitate tracer extraction. The extractant was then vacuum-filtered through a filtration system of glass vessels and a $0.45-\mu \mathrm{m}$ Gelman Supor hydrophilic polyethersulfone membrane filter. Previous testing with the filtration system using the dye solutions showed a negligible mass loss for the potentially sorbing dyes; the recovery percentages were $96.1 \pm 6.3 \%$ for FD\&C Blue No. 1 and $99.0 \pm 5.5 \%$ for Sulpho Rhodamine B.

The tracer concentrations were presented on the basis of oven-dried weight of rock samples, with the gravimetric moisture content determined by drying the samples at $105-110^{\circ} \mathrm{C}$. The background levels for each tracer were measured by taking clean rock samples that had not been exposed to tracers and subjecting these samples to the same extraction procedures as the contaminated samples. Evaluation studies, conducted by spiking sieved samples with a known amount of tracer, indicated that the efficiency of this extraction procedure was $97.6 \% \pm 2.1 \%$ (from eight replicates) for iodide, $96.9 \% \pm 1.9 \%$ for bromide, and $78.7 \% \pm 2.7 \%$ for FD\&C Blue No. 1 . The sample-processing procedure was not designed to measure total tracer mass; relative measurements by using the identical procedure for both clean and contaminated rock samples were sufficient for the objective of this study.

Aqueous tracer measurement The filtrates were analyzed using various methods to identify the presence of tracers, and independent analyses were conducted to evaluate the potential interference between tracers present in the same sample. Analyses of iodide and bromide were conducted using ion-specific electrodes (Ionplus Design, Orion). The iodide measurements were sensitive to the aqueous iodide concentration but were insensitive to other tracers applied at the niche. The analyses of the bromide con- centrations in some samples were also performed by ion chromatography (Model DX-120, Dionex Corp.) using an IonPac AS14 analytical column with an eluting solution of $3.5 \mathrm{mM} \mathrm{Na}_{2} \mathrm{CO}_{3}$ and $1.0 \mathrm{mM} \mathrm{NaHCO}$. A $25-\mu \mathrm{L}$ sample volume was used, and the method detection limit was determined to be $0.05 \mathrm{mg} / \mathrm{L}$ for bromide.

The dye tracers present in the sample extracts were identified and quantified by (1) inspecting the color of each extracted sample; (2) "fingerprinting" the sample with ultraviolet-visible (UV/Vis) scanning, where the sample spectra were compared to and matched to those of standard solutions that exhibit characteristic wavelengths (listed as identification peaks in Table 3); and (3) quantifying the concentration at the individual maximum/optimal wavelength for each dye. A UV/Vis spectrophotometer (Model U-2001, Hitachi) or a fluorescence spectrophotometer (Model RF-1501, Shimadzu) was used to measure the dyes; the quantification wavelengths are presented in Table 3. The dye detection limits of the UV/ Vis spectrophotometer are roughly equal to the lowestcolor density in solutions that the naked eye can resolve. The detection limit for the fluorescence spectrophotometer is about $0.6 \mu \mathrm{g} / \mathrm{kg}$, which is about 20 times lower than that for the UV/Vis spectrophotometer.

The tracer data are presented in Table 3 as ratios of the detected tracer level to the background level; higher ratios indicate stronger tracer presence. This ratio approach provided sufficient information about the spatial distributions of the tracers from the borehole samples and reconciled the difference in measurement-detection sensitivities between the UV/Vis and fluorescence spectrophotometers.

Column experiments A clean tuff block was collected within the same hydrogeologic unit as Niche 3650. Rock from this block was processed for size reduction, and a 0.5-2 mm size fraction was used for column transport studies. A Plexiglas column (3.8-cm inner diameter, 15.0$\mathrm{cm}$ length) was incrementally packed with the air-dried, crushed tuff to obtain a uniform bulk density. After the packed column was evacuated, an electrolyte solution composed of $192 \mathrm{mg} / \mathrm{L} \mathrm{NaHCO}_{3}$ and $3 \mathrm{mg} / \mathrm{L} \mathrm{Na}_{2} \mathrm{CO}_{3}$ was

Table 3. Analytical measurement for liquid-dye tracers

\begin{tabular}{llcc}
\hline Dye tracer & $\begin{array}{l}\text { Identification peaks in } \\
\text { UV/Vis spectrum (nm) }\end{array}$ & $\begin{array}{c}\text { Quantification peak in } \\
\text { UV/Vis spectrophotometer (nm) }\end{array}$ & $\begin{array}{c}\text { Quantification wavelengths in } \\
\text { fluorometric analysis (nm) }\end{array}$ \\
\hline FD\&C Blue No. 1 & $307,408,630$ & 630 & \\
FD\&C Yellow No. 5 & 257,426 & 426 & \\
FD\&C Yellow No. 6 & $234,313,482$ & 482 & \\
FD\&C Red No. 40 & $211,234,314,504$ & 504 & Excitation: 565; Emission: 590 \\
Sulpho Rhodamine B & $198,259,284,353,565$ & & Excitation: 405; Emission: 515 \\
Pyranine & $246,289,369,403$ & & Excitation: 420; Emission: 515 \\
Acid Yellow 7 & $231,275,419$ & & Excitation: 355; Emission: 445 \\
Amino G Acid & $219,247,304,348$ & & \\
\hline
\end{tabular}


introduced to the column to achieve full saturation. This electrolyte solution mimicked the groundwater at Yucca Mountain.

The apparatus and methods employed for the miscible displacement studies were similar to those used in previous studies (Hu and Brusseau, 1995). One HPLC pump (SSI Acuflow series I) was connected to the column, with a three-way switching valve placed in-line to facilitate switching between solutions with and without the solute of interest. Column effluent fractions were collected with an automated fraction collector (Pharmacia RediFrac), and the solute concentrations in the effluent samples were analyzed by the methods described above. The transport of the solute was investigated for all tracers used in the field tests. The input concentrations for the tracers were about $50 \mathrm{mg} / \mathrm{L}$, and a flow rate of 1.0 $\mathrm{mL} / \mathrm{min}$ was used for the experiments.

\section{RESULTS AND DISCUSSION}

\section{Tracer-migration test}

No iodide, bromide, or FD\&C Yellow No. 5 concentrations above the background levels were detected in the core samples collected from the 12 sampling boreholes. Iodide and FD\&C Yellow No. 5 were applied only during the tracer-migration test. Bromide was introduced at a release concentration of $3,700 \mathrm{mg} / \mathrm{L}$, which is much higher than its concentration (about $18 \mathrm{mg} / \mathrm{L}$ ) in the mine water used for all liquid-release tests and construction activities at ESF. These results indicated that the sampling borehole array circumscribed the liquid plume of the tracer-migration test. The tracer migration was most likely localized and very possibly confined to the $1.0 \times 1.6-\mathrm{m}$

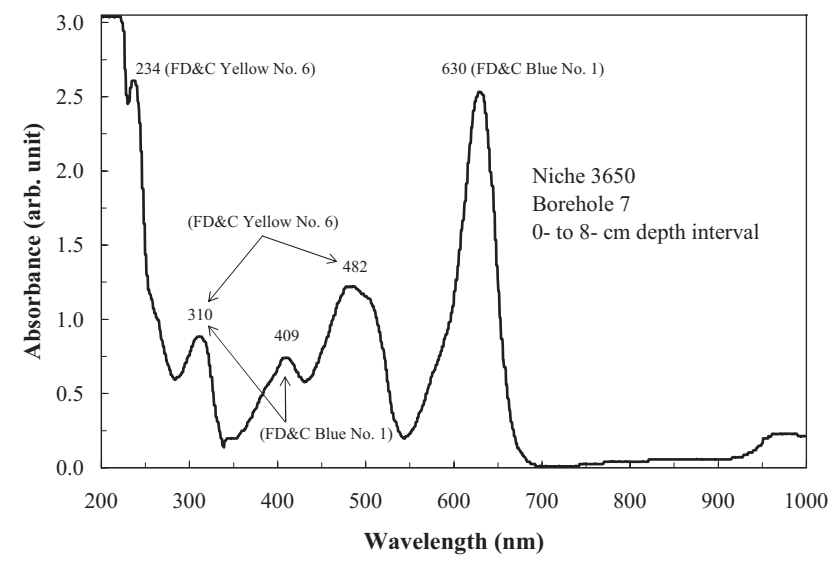

Fig. 3. UV/Vis wavelength scanning of an extractant sample (borehole 7, 0- to 8-cm interval location from the borehole collar). The numbers in this figure are given in nanometers, and each identified dye is indicated in parentheses. area (within sampling boreholes 2, 6, 7, and 11 as shown in Fig. 2b) directly below the liquid-release interval for the tracer-migration test.

Extra effort was expended to identify the presence of dyes used both before and during the tracer-migration test. For example, some sample extractants from borehole 7 appeared yellowish, and UV/Vis scans were run for these samples to compare the spectra with those for standard dye solutions. Figure 3 shows the spectra of one sample (borehole 7,0- to 8-cm depth interval from the borehole collar). Peak-matching with the characteristic wavelengths of the standards (see Table 3) showed that FD\&C Blue No. 1 and FD\&C Yellow No. 6 were present in this sample, while FD\&C Yellow No. 5 was absent. Similarly, the yellowish color from borehole 11 extractants was found to be from Pyranine, rather than from FD\&C Yellow No. 6 or FD\&C Yellow No. 5.

During the tracer-migration test, the wetting front was observed to reach the niche ceiling in a large fracture or breakout, but water did not drip into the niche. Breakout refers to a location where a block of rock falls out of the ceiling during the niche mining process, producing a void that extends upward beyond the relatively flat section of the ceiling. Trautz and Wang (2002) reported that the niche ceiling serves as a capillary barrier to prevent liquid seepage into the niche, especially for tests with a limited liquid-release volume and a low release rate, like our tracermigration test. If the release rate is fast enough to overcome the capillary barrier effect of the niche ceiling, seepage will be observed, as shown from the consistent relationship between the rate of release and the seepage mass captured for nearly identical liquid-release volumes in this test interval (see Table 2). Evaporation due to tunnel ventilation will also affect seepage behavior. Active ventilation in the tunnel combined with low release rates will prevent the development of liquid droplets on the niche ceiling, and consequent dripping into the niche.

Rock-chip samples from the niche ceiling were collected and analyzed, and the results showed a high concentration of iodide and bromide among all six samples. For example, the measured iodide concentration ranged from 1.5 to $83.7 \mathrm{~g} / \mathrm{kg}$, while the background concentration was $0.02 \mathrm{~g} / \mathrm{kg}$. These results confirmed that the tracers had arrived within the wetting front observed at the niche ceiling during the tracer-migration test and had spread on the ceiling. FD\&C Yellow No. 5 was not found among these rock-chip samples, possibly because its transport was delayed by interactions in the flow pathways. FD\&C Blue No. 1, FD\&C Yellow No. 6, FD\&C Red No. 40, Sulpho Rhodamine B, Amino G Acid, Pyranine, and Acid Yellow 7 were all detected in these samples, as they were used in various early tests. The distribution behavior of these tracers will be discussed in more detail in the next section. 


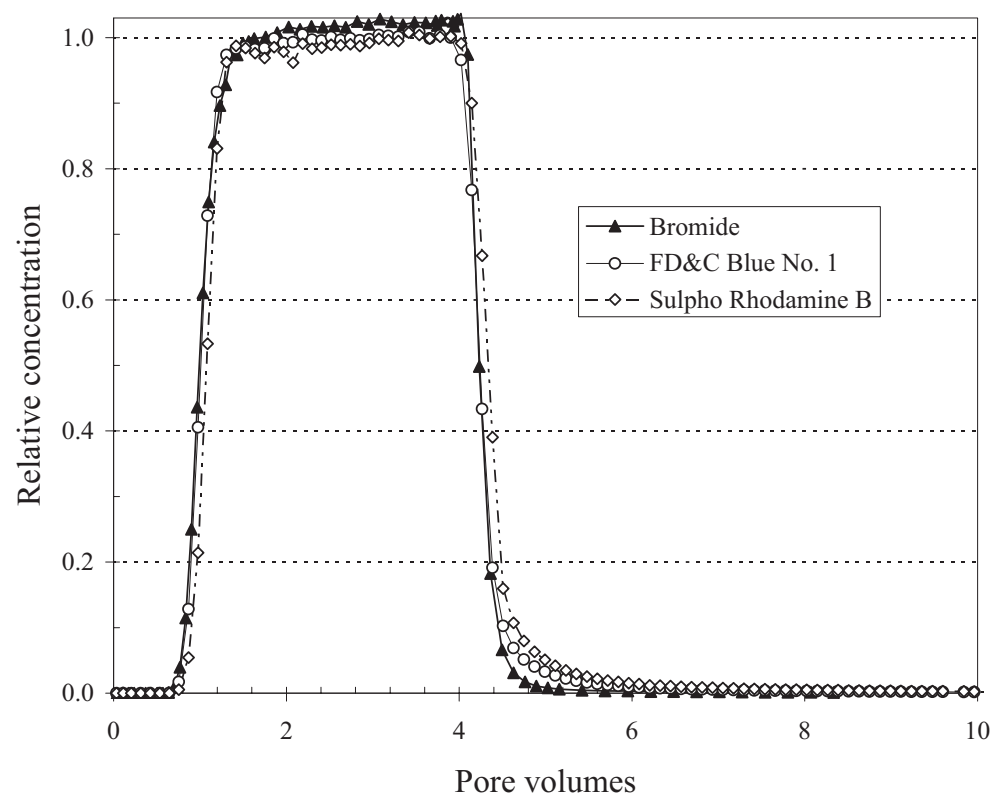

Fig. 4. Breakthrough curves for transport of bromide, FD\&C Blue No. 1, and Sulpho Rhodamine B, from a pulse injection through a crushed-tuff column.

Table 4. Measured tracer retardation factor

\begin{tabular}{lc}
\hline Tracer & Retardation factor \\
\hline Bromide & 1.000 \\
Iodide & 1.026 \\
FD\&C Blue No. 1 & 1.075 \\
FD\&C Yellow No. 5 & 0.971 \\
FD\&C Yellow No. 6 & 1.013 \\
FD\&C Red No. 40 & 1.071 \\
Sulpho Rhodamine B & 1.166 \\
Pyranine & 1.033 \\
Acid Yellow 7 & 1.057 \\
Amino G Acid & 1.014 \\
\hline
\end{tabular}

The transport behavior of all tracers was investigated in a saturated column packed with crushed tuff. Because crushed tuff is not representative of fractured intact tuff in the field, which might be coated with minerals (Carlos et al., 1995), the main purpose of this study was to examine the sorption behavior and the extent of dyes with tuff matrix. The breakthrough curves for the transport of bromide, as well as the transport of FD\&C Blue No. 1 and Sulpho Rhodamine B, are shown in Fig. 4 as examples. The breakthrough curves for all dyes, except FD\&C Yellow No. 5, appear slightly delayed when compared with those for bromide, which has been confirmed as being nonreactive with tuff with a retardation factor of 1.0 (see Table 4). This slight delay indicates a very weak sorption of these dyes by the tuff matrix.

\section{Tracer distribution delineation}

Several dyes applied during previous liquid-release tests were detected in the borehole samples, as summarized in Table 5. FD\&C Blue No. 1, which was used both before and during the tracer-migration test, was present at 7 out of 12 boreholes; some boreholes had relatively high concentrations of the dye. In comparison, Sulpho Rhodamine B was detected in four borehole samples. Overall, the dye distribution pattern was relatively spotty, reflecting the complex interplay of preferential flow paths and liquid application history. Examples of measured dye concentration versus the depth interval from the borehole collar are shown in Figs. 5 and 6.

To illustrate the spatial distribution of tracer detection with respect to its application location, we plotted the measured tracer distributions (presented as a dimensionless ratio on the basis of background concentration) in three dimensions, based on the as-built survey coordinates of the boreholes.

FD\&C Blue No. 1 was released in six intervals during pre-excavation liquid-release tests and in four intervals during post-excavation seepage tests. The blue-dye distributions, together with release-interval locations, are illustrated in Fig. 7. The wide lines represent boreholes in which tracer was detected; the narrow lines represent boreholes in which no tracer was detected. The multiple application of FD\&C Blue No. 1 made it difficult to link its detection to its original release location. Overall results, however, suggested that most of the blue-dye detection was associated with nearby release intervals. For 
Table 5. Compilation of dye detection at different sampling boreholes

\begin{tabular}{|c|c|c|c|c|c|c|}
\hline Borehole ID & FD\&C Blue No. 1 & Sulpho Rhodamine B & FD\&C Yellow No. 6 & Pyranine & Acid Yellow 7 & Amino G Acid \\
\hline 1 & - & (b) & - & - & - & - \\
\hline 2 & (b) & - & - & - & (c) & (a) \\
\hline 3 & (b) & - & - & - & - & - \\
\hline 4 & - & - & - & - & - & - \\
\hline 5 & - & - & - & - & - & - \\
\hline 6 & - & - & - & - & - & - \\
\hline 7 & (c) & (c) & (b) & - & - & - \\
\hline 8 & (b) & - & - & - & - & - \\
\hline 9 & (a) & - & - & - & - & - \\
\hline 10 & (b) & (c) & - & (a) & - & - \\
\hline 11 & (c) & (a) & - & (b) & - & - \\
\hline 12 & - & - & - & - & - & - \\
\hline
\end{tabular}

-: Detection ratio $<3$ (treated as not present).

(a): The highest detection ratio is between 3 and 100 within the borehole.

(b): The highest detection ratio is between 100 and 1000 within the borehole.

(c): The highest detection ratio is $>1000$ within the borehole.

example, the strong presence of FD\&C Blue No. 1 at boreholes 7, 8, 10, and 11 (Table 5) can all be correlated to its release history near those boreholes.

Similar to FD\&C Blue No. 1, Sulpho Rhodamine B was used extensively in eight seepage tests along seven borehole intervals. Near borehole 7, Sulpho Rhodamine B was released only once in the interval of UM 4.88$5.18 \mathrm{~m}$ (4.88-5.18 $\mathrm{m}$ from the borehole collar), followed by four elution episodes: three liquid-releases without dyes and one with green dye (a mixture of FD\&C Blue No. 1 and FD\&C Yellow No. 6). The presence of Sulpho Rhodamine B in borehole 7 most likely originated from this release event (see Table 2). Sulpho Rhodamine B was not detected in boreholes 3, 9, and 12. This finding suggests that Sulpho Rhodamine B was likely migrating downward, rather than spreading laterally, from the ensuing elution episodes.

The observations of localized tracer distribution and downward migration were confirmed by the distribution of four other dyes applied before the tracer-migration test. Pyranine, Acid Yellow 7, and Amino G Acid had been applied only once at the niche. FD\&C Yellow No. 6 was used once at UM 4.88-5.18 m within the sampling borehole array and another time at UL 7.62-7.92 m, outside the borehole array (see Fig. 2a). The presence of these four dyes in the sampling borehole array maps the extent of lateral tracer spreading in the rock. Pyranine was detected at the nearby boreholes 10 and 11 , with its presence much lower at borehole 10 than at borehole 11 (see Table 2 and Fig. 8). Borehole 11 is located almost exactly below the interval of UM 4.27-4.57 $\mathrm{m}$, where Pyranine was released. Four episodes of water-only seepage tests were conducted following this Pyranine application. Similar to Sulpho Rhodamine B at borehole 7, these liquid releases did not seem to enhance the exten- sive lateral spreading of Pyranine. Instead, these five intermittent release tests caused the lateral spreading of Pyranine to be at most about $0.75 \mathrm{~m}$ to the left of the application interval, as shown from its detection at borehole 10. However, its presence at borehole 10 was only slightly above its background level. These results consistently show the predominantly downward flow paths in the unsaturated fractured rock. It seems that the ensuing plumes from multiple episodic pulses follow the flow paths (predominantly downward) established earlier and do not spread the tracer further away in a lateral direction.

Glass et al. (2002) observed similar flow phenomena in the laboratory experiments using a fracture-matrix network made of a brick wall. Preferential flow pathways evolved within the fracture network, even in the presence of the strong capillary forces associated with a highly porous matrix. The fractures, which acted as both flow conductors and capillary barriers, tended to constrain the flow in each pathway to a narrow lateral zone. The flow in the fractures was predominantly gravity-driven, with an overall wetted plume that was elongated in the direction of gravity. Glass et al. expected such behavior to exist, with an increase in strength, for a fracture-matrix network with a less permeable rock matrix in combination with the wider fractures, such as the welded tuff of Yucca Mountain. Our field-scale tracer-migration experiments are consistent with their prediction.

Acid Yellow 7 was detected only at borehole 2, which was about $0.3 \mathrm{~m}$ from UM $6.10-6.40 \mathrm{~m}$, where it was released. Amino G Acid was also detected just slightly above its background level at borehole 2, which was about $0.3 \mathrm{~m}$ from UM 5.49-5.79 m, where it was released. Note that although the UM 5.49-5.79 m release interval was encompassed within the sampling borehole array, no other 

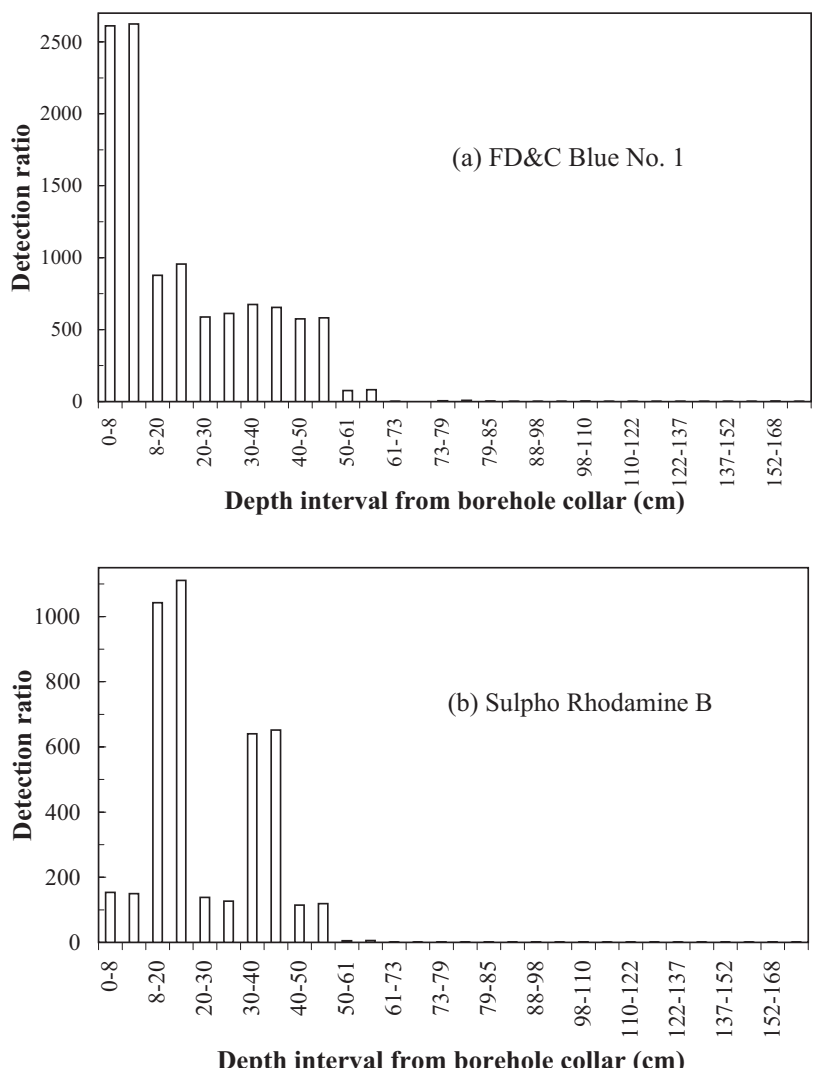

Fig. 5. Dye detection in the extractant of rock samples along borehole 7: (a) FD\&C Blue No. 1. (b) Sulpho Rhodamine B. Detection ratio (dimensionless) is the ratio of the detected tracer concentration divided by its background concentration.

sampling boreholes detected Amino G Acid.

FD\&C Yellow No. 6 was present to a large extent at borehole 7 (Table 2). Borehole 7 was about $0.5 \mathrm{~m}$ to the right from UM 4.88-5.18 m, where both FD\&C Yellow No. 6 and FD\&C Blue No. 1 were simultaneously released. Of all the liquid-release tests conducted at the niche, this release episode was among the slowest $(0.013$ $\mathrm{mL} / \mathrm{s}$ ) and released the largest volume of liquid (5597 $\mathrm{mL}$ ). Borehole 7 was located in the middle of the sampling borehole array. The sole presence of FD\&C Yellow No. 6 in borehole 7 further demonstrates the localized characteristics of liquid flow with limited lateral spreading, even with a comparatively large release volume.

FD\&C Red No. 40 was used in four test intervals of UL and UM boreholes before the niche excavation. However, this dye was not detected in any of the core samples from the 12 drilling boreholes; reasons for this finding are unknown. The dye may have degraded, either abiotically or biologically, during the seven-month time period between applying the dye and drilling the sampling borehole. However, a laboratory column transport test of FD\&C Red No. 40 that lasted nearly eight hours
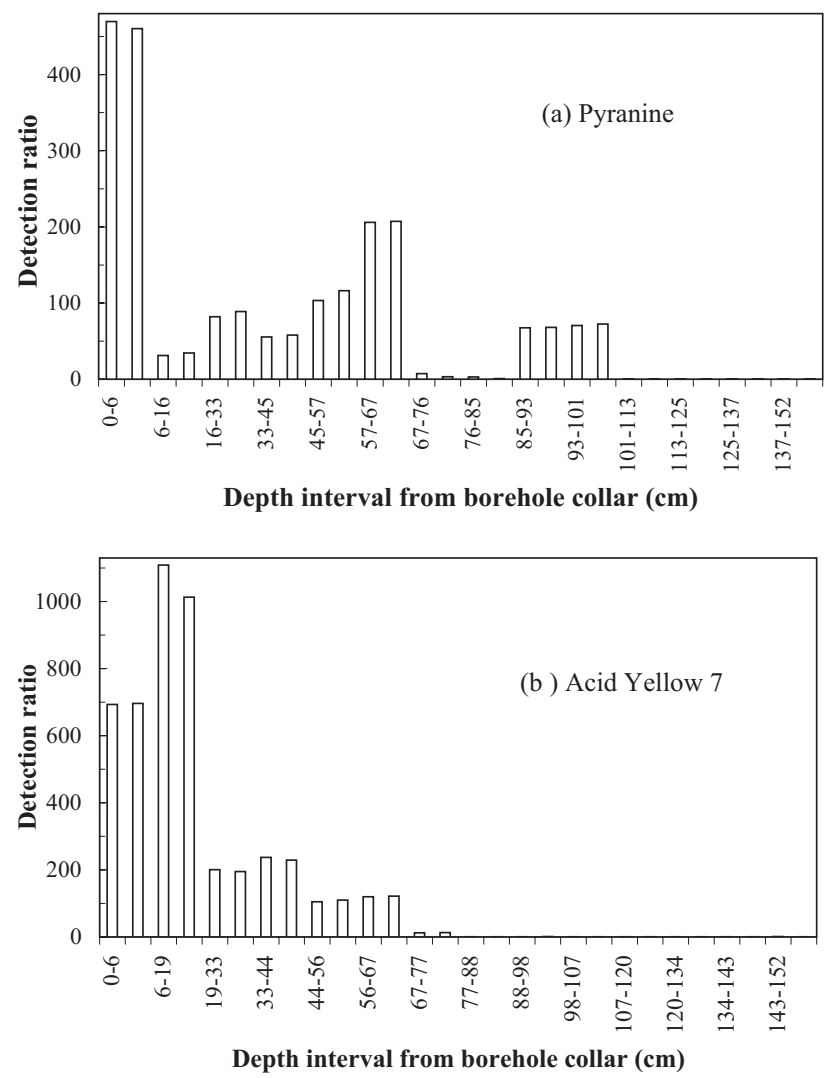

Fig. 6. Dye detection of (a) Pyranine along borehole 11 and (b) Acid Yellow 7 along borehole 2.

did not indicate any mass loss. It is also possible that this dye has a high affinity to the fracture-coating minerals present in the flow pathways.

From pneumatic tests, Wang et al. (1999) reported an approximately 200-times increase for the mean permeability in various test intervals within the UM borehole after excavation construction. This increase was attributed to the fractures opened by the stress relief associated with niche excavation, which results in a mechanically induced increase in permeability values. This permeability enhancement seems to be more prominent for test intervals with an initially low permeability. For example, the air permeability at UM $5.49-5.79 \mathrm{~m}$ increased from $2.8 \times 10^{-14}$ to $1.6 \times 10^{-12} \mathrm{~m}^{2}$, while for the initially permeable UM $4.88-5.18 \mathrm{~m}$ - the location of the tracermigration test - the air permeability increased only from $3.2 \times 10^{-11}$ to $1.9 \times 10^{-10} \mathrm{~m}^{2}$ (table 1 of Wang et al., 1999). The effect of the permeability increase on tracer transport is probably minor, as fractures serve as the predominant transport pathways at the test site, and the fracture permeability is large enough to transport tracers rapidly without being affected by an additional permeability increase. 


\section{FD\&C Blue No.1}
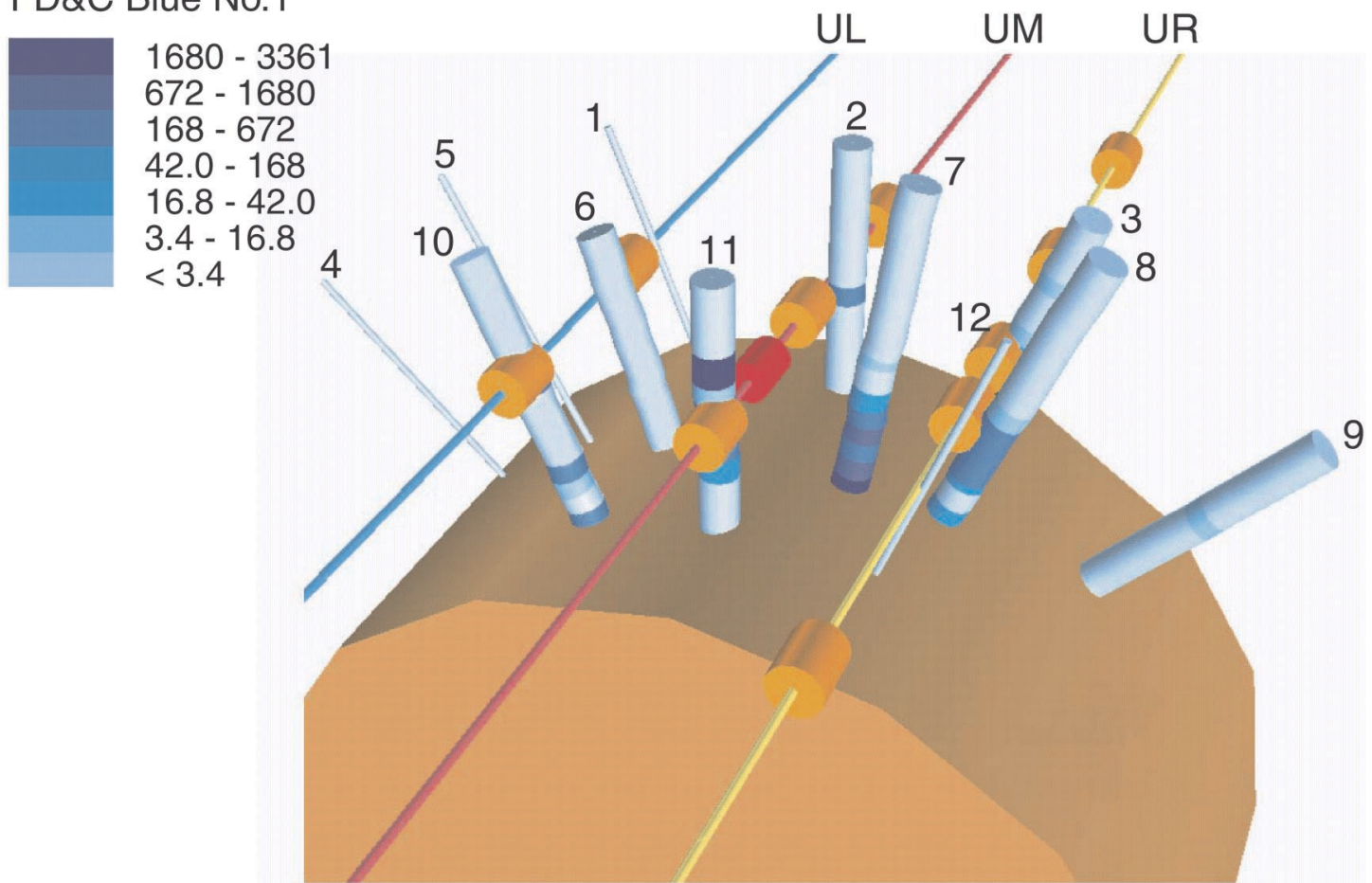

Fig. 7. A three-dimensional view of FD\&C Blue No. 1 detection related to the release intervals above the niche. The red-colored cylinder denotes the tracer-release interval; the orange cylinders denote the intervals of early release events. Each sampling borehole is identified. The figure legend shows the detection ratio (dimensionless), which is the ratio of the detected tracer concentration divided by its background concentration.

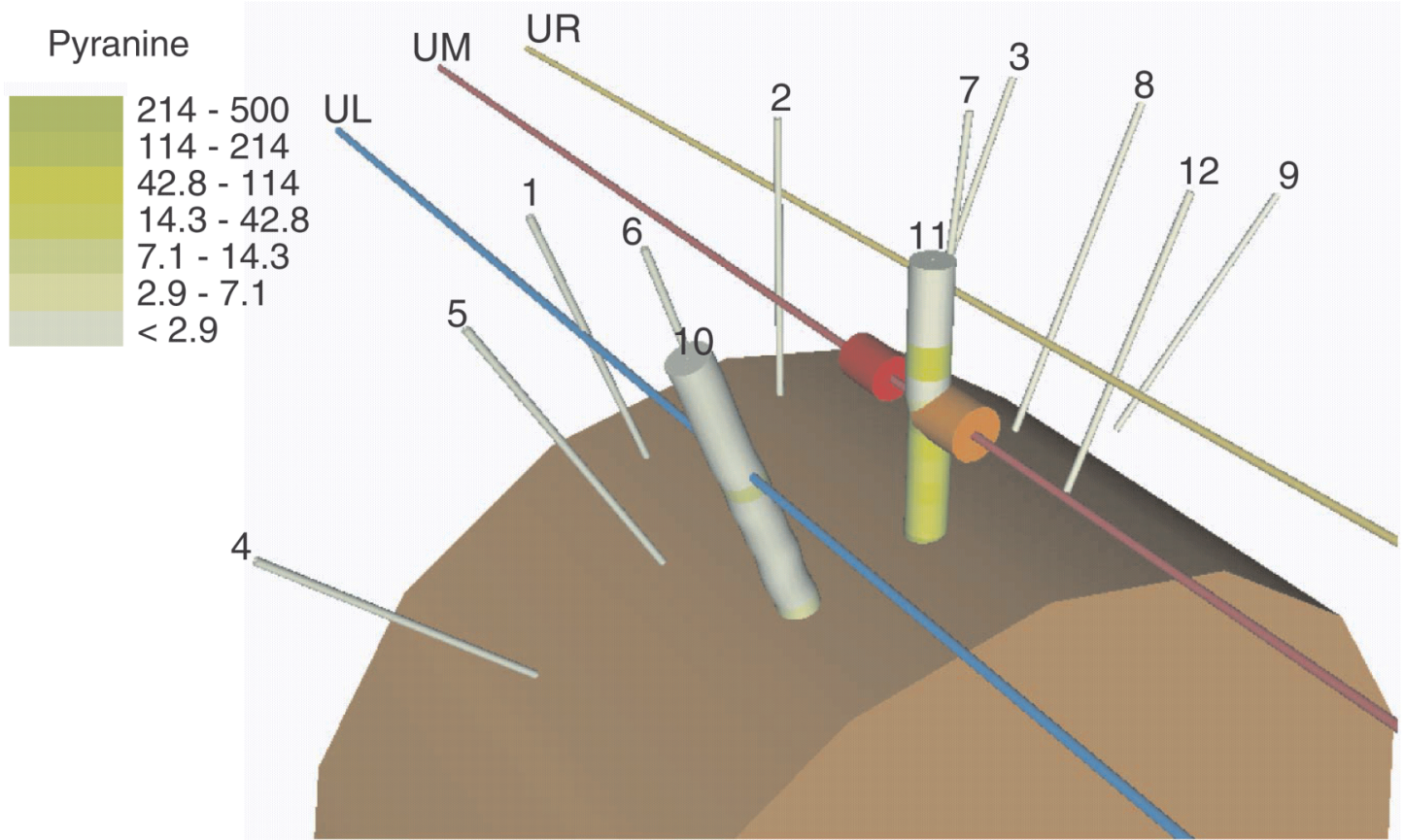

Fig. 8. A three-dimensional view of Pyranine detection related to the release interval above the niche (refer to Fig. 7 caption). 
The overall findings of limited lateral spreading for the tracers, from the core drilling and sampling, are consistent with other observations of niche excavation and post-excavation seepage behavior. Niche-excavation results showed that the dyes applied during the preexcavation tests exhibited a vertical penetration distance that was greater than the extent of lateral spreading (Wang et al., 1999). For example, FD\&C Blue No. 1, which was applied at UM 4.27-5.79 $\mathrm{m}$ with an injected volume of $1,008.7 \mathrm{~mL}$, was observed to have a maximum penetration depth of $1.68 \mathrm{~m}$ and a maximum lateral extent of $0.87 \mathrm{~m}$, with an aspect ratio of 1.93. FD\&C Red No. 40, which was applied at UM 4.88-5.18 m with an injected volume of $1,033.1 \mathrm{~mL}$, had a $0.86-\mathrm{m}$ maximum penetration and a $0.37-\mathrm{m}$ lateral extent, with an aspect ratio of 2.32. These pre-excavation migration tests did not have vertical boundaries because the niche had not been constructed at the time of the tests. Furthermore, during postexcavation liquid-release tests to study the capillary barrier effect and seepage threshold, the liquid that seeped into the niche was captured directly beneath, or immediately adjacent to, the test interval. These results are consistent with a gravity-driven flow in fractures and a possibly elongated tracer plume in the direction of gravity.

The dye distribution plots also indicated that several dyes might migrate above the injection intervals, as illustrated in Figs. 7 and 8 for FD\&C Blue No. 1 and Pyranine. This is a potentially important observation, indicating that strong capillary forces (i.e., imbibition) in the tuff matrix may induce upward movement against gravity. This could happen in a test interval where there are no interconnected fractures to enable gravitydominated flow. The upward-flow phenomenon has also been observed in the Busted Butte work of Yucca Mountain, where rock is less fractured and matrix flow is dominant (Bussod et al., 1998). Furthermore, Hu et al. (2002) presented an unsaturated-transport sorption method to examine the upward tracer movement in a tuff core that was hung and its bottom touched a tracer solution. Dye detection at an apparently deeper depth interval can also be partly attributed to an inaccurate subsample depth interval, as the spatial resolutions for fragmented core samples may be poor. For example, FD\&C Blue No. 1 and Pyranine were detected at relatively high concentrations in the depth interval of $66.6-99.8 \mathrm{~cm}$ for borehole 11 (Figs. 7 and 8); the core sample of this depth interval consists of highly fractured pieces.

\section{SUMMARY}

Migration tests using multiple tracers were conducted in unsaturated fractured tuff in a mined niche, Niche 3650, at the ESF in Yucca Mountain, Nevada. Of the 60 total liquid-release tests over 16 borehole intervals at Niche
$3650,60 \%$ used tracers, while the remaining tests used only water. The tracer distributions were evaluated by analyzing core samples collected from the 12 boreholes drilled into the flow domains, as well as the rock chips collected from the niche ceiling. Results from the tracermigration test suggested a localized migration behavior, with the plume confined within the $1.0 \times 1.6-\mathrm{m}$ area directly below the liquid-release interval. The nondetection of iodide, bromide, and FD\&C Yellow No. 5 within the sampling borehole array may possibly (although not likely) indicate that these tracers simply bypassed the sampling array via undetected fracture flow. The dye tracers may also have been sorbed by the tuff matrix, as shown from their detectable-although weak-sorption in the crushed tuff. The spatial distribution of dye tracers from the previous liquid-release applications consistently points to localized flow paths with limited lateral spreading of dye migration during an episodic flow of limited volume. Multiple episodic pulses did not spread the applied tracers further away, and the ensuing plumes appeared to follow the flow paths established earlier.

Acknowledgments-The authors appreciate Randy Hedegaard of Lawrence Berkeley National Laboratory (LBNL) for plotting the three-dimensional Earth Vision figures, and Boris Faybishenko and Dan Hawkes of LBNL for many helpful comments. We are grateful for comments provided by Emmeline Chen of Lawrence Livermore National Laboratory. We also greatly appreciate constructive comments from two reviewers. This work was supported by the Director, Office of Civilian Radioactive Waste Management, U.S. Department of Energy, through Memorandum Purchase Order EA9013MC5X between Bechtel SAIC Company, LLC, and the Ernest Orlando Lawrence Berkeley National Laboratory.

\section{REFERENCES}

Bussod, G. Y., Coen, K. and Eckhardt, R. C. (eds.) (1998) LA testing status report: Busted Butte unsaturated zone transport test (FY 98). Yucca Mountain Project milestone report SPU85M4. September 30, 1998. Los Alamos National Laboratory, Los Alamos, New Mexico.

Carlos, B. A., Chipera, S. J. and Bish, D. L. (1995) Distribution and chemistry of fracture-lining minerals at Yucca Mountain, Nevada. LA-12977-MS. Los Alamos National Laboratory, Los Alamos, New Mexico.

Faybishenko, B., Doughty, C., Steiger, M., Long, J. C. S., Wood, T. R., Jacobsen, J. S., Lore, J. and Zawislanski, P. T. (2000) Conceptual model of the geometry and physics of water flow in a fractured basalt vadose zone. Water Resour. Res. 36, 3499-3520.

Flury, M. and Fluhler, H. (1995) Tracer characteristics of brilliant blue FCF. Soil Sci. Soc. Amer. Jour. 59, 22-27.

Glass, R. J., Nicholl, M. J., Pringle, S. E. and Wood, T. R. (2002) Unsaturated flow through a fracture-matrix network: Dynamic preferential pathways in mesoscale laboratory experi- 
ments. Water Resour. Res. 38, No. 12, 1281, DOI:10.1029/ 2001WR001002.

$\mathrm{Hu}$, Q. and Brusseau, M. L. (1995) The effect of solute size on transport in structured porous media. Water Resour. Res. 31, 1637-1646.

Hu, Q., Kneafsey, T., Trautz, R. C. and Wang, J. S. Y. (2002) Tracer penetration into welded tuff matrix from flowing fractures. Vadose Zone J. 1, 102-112.

Kasnavia, T., Vu, D. and Sabatini, D. A. (1999) Fluorescent dye and media properties affecting sorption and tracer selection. Ground Water 37, 376-381.

McLaughlin, M. J. (1982) A review of the use of dyes as soil water tracers. Water SA 8, 196-201.

Nicholl, M. J., Glass, R. J. and Wheatcraft, S. W. (1994) Gravity-driven infiltration instability in initially dry nonhorizontal fractures. Water Resour. Res. 30, 2533-2546.

Pruess, K. (1998) On water seepage and fast preferential flow in heterogeneous, unsaturated rock fractures. J. Contam. Hydrol. 30, 333-362.
Pruess, K. (1999) A mechanistic model for water seepage through thick unsaturated zones in fractured rocks of low matrix permeability. Water Resour. Res. 35, 1039-1051.

Smart, P. L. and Laidlaw, I. M. S. (1977) An evaluation of some fluorescent dyes for water tracing. Water Resour. Res. 13, 15-33.

Su, G., Geller, J. T., Pruess, K. and Wen, F. (1999) Experimental studies of water seepage and intermittent flow in unsaturated, rough-walled fractures. Water Resour. Res. 35, 1019-1037.

Tokunaga, T. K. and Wan, J. (1997) Water film flow along fracture surfaces of porous rock. Water Resour. Res. 33, 12871295.

Trautz, R. C. and Wang, J. S. Y. (2002) Seepage into an underground opening constructed in unsaturated fractured rock under evaporative conditions. Water Resour. Res. 38, No. 12, 1188, DOI:10.1029/2001WR000690.

Wang, J. S. Y., Trautz, R. C., Cook, P. J., Finsterile, S., James, A. L. and Birkholzer, J. (1999) Field tests and model analyses of seepage into drift. J. Contam. Hydrol. 38, 323-347. 